\title{
Experimental Study on Nail Joint Shearing Properties of Light Frame Wooden Shear Walls
}

\author{
Zhenhua Han", Weibo Dong, Boqi Song \\ Engineering General Institute of Shanghai Construction Group, Shanghai, China \\ Email address: \\ hanzhenhua_520@126.com (Zhenhua Han),web55@qq.com (Weibo Dong), tgsobq@126.com (Boqi Song) \\ ${ }^{*}$ Corresponding author
}

To cite this article:

Zhenhua Han, Weibo Dong, Boqi Song. Experimental Study on Nail Joint Shearing Properties of Light Frame Wooden Shear Walls. Engineering and Applied Sciences. Vol. 3, No. 4, 2018, pp. 113-120. doi: 10.11648/j.eas.20180304.13

Received: September 29, 2018; Accepted: October 22, 2018; Published: November 12, 2018

\begin{abstract}
Shear walls in light wooden frame structure are major components to resist lateral loading. Nail joint is one of the most important factors that affects shear walls shearing properties. In this paper, different nail types, sheathing panel types and thickness and stud grain direction were set to study the influence factors of nail joint properties. Wooden shear walls made of studs with different cross size were monotonic and cyclic loaded to investigate the influence on lateral resistance properties. The failure of nail joint can be classified into three modes that nails bent and withdrawn from the studs, nail heads pulled off from the panels and nails split off along the stud grain. It is concluded from the nail joint loading and displacement results that twist nails get the largest bearing capacity compared with strip nails and coil nails due to the nail diameter and larger friction. Nail joints on China-produced structural plywood obtain the largest shearing resistance values among three different kinds of panels. And thicker panels can bear larger shearing loadings. The largest displacement of the nail joints load parallel to stud grain were larger than those perpendicular to stud grain. It can be derived from the shear wall lateral loading experiments that the lateral resistance of the shear wall could not be strengthened with the larger stud size, while the stiffness and energy capacity could be improved. In this way, the seismic resistance properties of shear walls can be enhanced by optimizing nail joint materials and studs parameters.
\end{abstract}

Keywords: Nail Joints, Failure Mode, Shearing Property, Shear Walls, Lateral Resistance

\section{Introduction}

Light wood frame construction is a kind of platform wooden frame structure that consists of wood trusses, walls and floors nail joint by dimensional lumber and overlaid wooden panels. It is extensively used in North America and Northern Europe due to its eco-friendly, indoor environmental behavior, energy efficiency, and seismic resistance characteristics. In 1990s, the light wood frame construction was firstly introduced to China and widely spread in economically developed coastal regions rapidly.

Shear walls are major components to resist lateral loading like wind and earthquake in light wood frame construction. The bearing capacity is mainly contributed by the sheeting structure that nail joint by studs and covering panels. The capacity of nail connection is the key factor that affects the mechanical behavior of shear wall and the whole structure. Plenty of experimental and theoretical researches have been done to study the nail connecting properties [1-4] and seismic behavior of timber joints with metal fasteners [5, 6]. In 1941, $\mathrm{K}$. W. Johansen firstly came up with the yielding theory by taking a large number of experiments and theory derivation that the capacity of nail connection is affected by nail ultimate flexural strength, shearing resistance strength and wood loading capacity at the nail joint points [7]. While different type of nails with various surface roughness, diameter and length contribute different static friction with wood nailing grooves [8-10]. Steel nails made of different materials contribute to various flexural and shearing strength [11]. Little research has been done on the influence of nails types.

The loading capacity of wooden panels at nailed point in related to panel types and grain direction. Lots of research have been done on the nail-holding ability of various panels $[12,13]$. According to Steve's research, there is significant 
difference between nail groove loading capacity along the radial direction and tangential direction [14]. However, the reason to the loading capacity difference is still unclear. Studs and sheathing panels connected by nails can provide large lateral resistance. The Chinese Standard GB 50005-2003 Code for design of timber structures [15] has presented the recommended value for shear wall stud, which is no less than $38 \times 89 \mathrm{~mm}$. However, it is not sure that larger stud size is correspond to better lateral shearing properties.

To present a guideline for wooden shearing walls material and structure design, different nail types, sheathing panel types and thickness and stud grain direction were set to study the influence factors of nail joint properties. Shear walls made of different cross size studs were tested to investigate the influence on lateral shearing properties.

\section{Materials and Method}

\subsection{Materials}

In North America, oriented strip boards (OSB) are mainly used as sheathing panel. While in Japan, structural plywood occupied the main position in walls and floors. In order to research the effect of different wood based panels, OSB imported from Canada, Chinese OSB (produced by Hubei Baoyuan Wood Industry Co. Ltd., average density $0.62 \mathrm{~g} / \mathrm{cm}^{3}$ ), and domestic structural plywood (SP) (produced by Hengxin (Linyi) Wood Industry Co. Ltd., $0.64 \mathrm{~g} / \mathrm{cm}^{3}$ ) (Figure 1) were utilized as sheathing panels. Samples were conditioned in $65 \% \mathrm{RH}$ and $20^{\circ} \mathrm{C}$ till moisture equilibrium before tests. The mechanical properties were measured in accordance to Chinese industrial standard LY/T 1580-2000 [16] and the results are showed in Table 1.

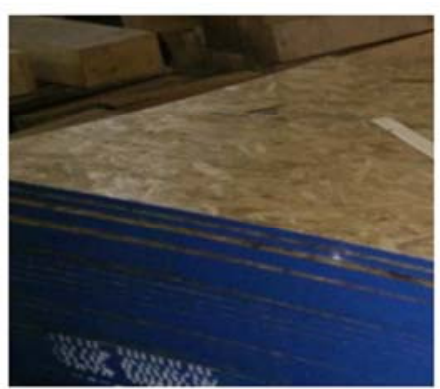

(a)

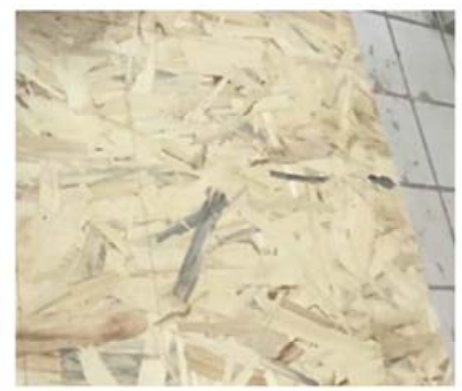

(b)

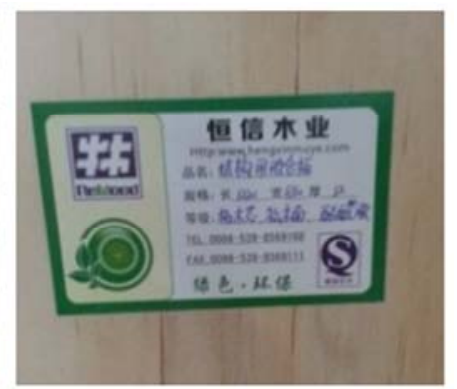

(c)

Figure 1. Sheathing panels: (a) Canadian OSB; (b) Domestic OSB; (c) Domestic structural plywood.

Table 1. Mechanical properties of sheathing panels.

\begin{tabular}{|c|c|c|c|c|c|}
\hline & & Cana & & Domestic OSB & Domestic SP \\
\hline \multicolumn{2}{|l|}{ Thickness /mm } & 9 & 12 & 12 & 12 \\
\hline \multirow{2}{*}{ MOE (MPa) } & Parallel & 5130 & 3710 & 7180 & 4690 \\
\hline & perpendicular & 2600 & 2000 & 1930 & 4640 \\
\hline \multirow{2}{*}{ MOR (MPa) } & Parallel & 35.0 & 21.0 & 51.5 & 43.7 \\
\hline & Perpendicular & 20.7 & 18.0 & 24.3 & 44.0 \\
\hline
\end{tabular}

The studs were made of lumber SPF (Spruce-Pine-Fir, imported from North America, average density $0.46 \mathrm{~g} / \mathrm{cm}^{3}, \mathrm{moisture}$ content $12.2 \%$, grade II). In order to study the influence of stud size on wall seismic resistance properties, studs with different cross size $38 * 89 \mathrm{~mm}$ and $38 * 140 \mathrm{~mm}$ were utilized to assemble shear walls, respectively.

As showed in Figure 2, coil nails $(78.51 \mathrm{~mm}$ in length, $2.82 \mathrm{~mm}$ in diameter), strip nails $(82.31 \mathrm{~mm}$ in length, $3.26 \mathrm{~mm}$ in diameter and $60.54 \mathrm{~mm}$ in length, $2.95 \mathrm{~mm}$ in diameter) and twist nails $(80.55 \mathrm{~mm}$ in length, $3.57 \mathrm{~mm}$ in diameter) were used to connect sheathing panels and studs. The strip nails and coil nails were driven by air nailer. The sheathing panels and studs were connected by the $60 \mathrm{~mm}$ nails. The top beam and studs were joint with $80 \mathrm{~mm}$ nails. (Figure 2)

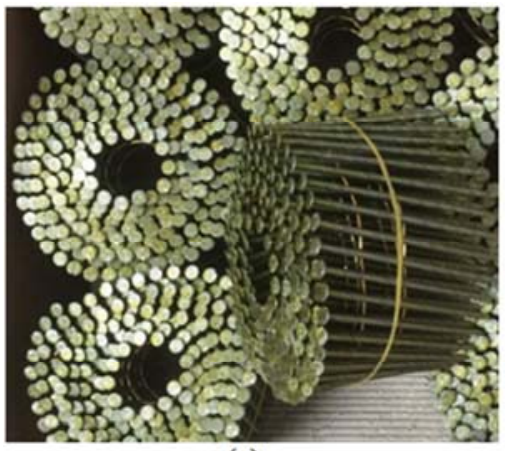

(a)

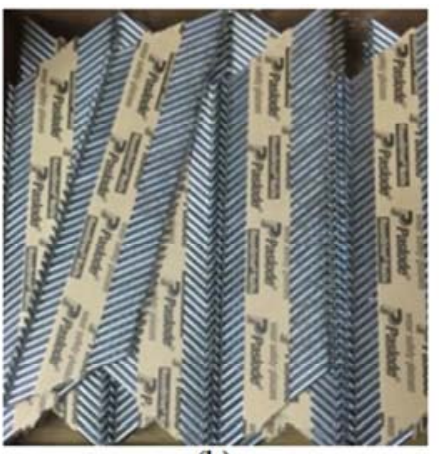

(b)

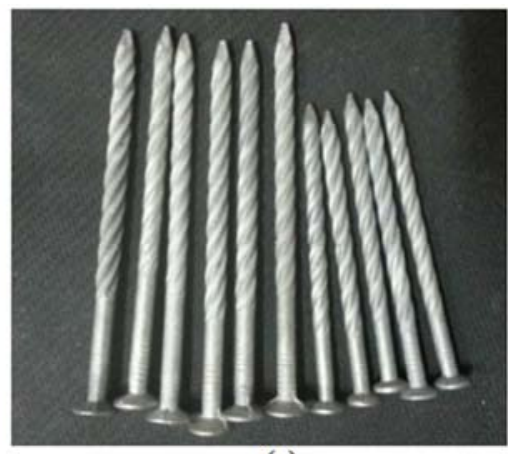

(c)

Figure 2. Framing nails: (a) coil nails; (b) strip nails; (c) twist nails. 


\subsection{Experiment Design}

\subsubsection{Nail Joints Shearing Test}

As showed in Table 2, comparison tests were designed based on the configurations of the nail joints, loading directions to the stud grain, panel thickness and panel types.
The panel size was $130 \mathrm{~mm} * 260 \mathrm{~mm}$, and the SPF studs length was $230 \mathrm{~mm}$ uniformly. The distance of nail joint points to the panel edge was $40 \mathrm{~mm}$. There were 12 groups and 6 specimens for each group. The configurations of nail joints for different loading direction to the grain are showed in Figure 3.

Table 2. Nail joints test scheme.

\begin{tabular}{llll}
\hline No. & Panel types & Panel thickness/mm & Nail types \\
\hline C12SA & Canadian OSB & 12 & strip \\
C12SE & Canadian OSB & 12 & Strip \\
C12CA & Canadian OSB & 12 & Coil \\
C12CE & Canadian OSB & 12 & Coil \\
C12TA & Canadian OSB & 12 & Twist \\
C12TE & Canadian OSB & 12 & Twist \\
D12SA & Domestic OSB & 12 & Strip \\
D12SE & Domestic OSB & Strip \\
C9SA & Canadian OSB & 12 & Strip \\
C9SE & Canadian OSB & 9 & Strip \\
P12SA & Domestic SP & 9 & Strip \\
P12SE & Domestic SP & 12 & Perpendicular \\
\hline
\end{tabular}

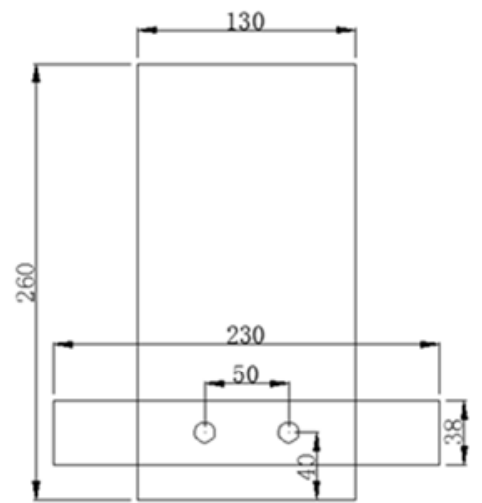

(a)

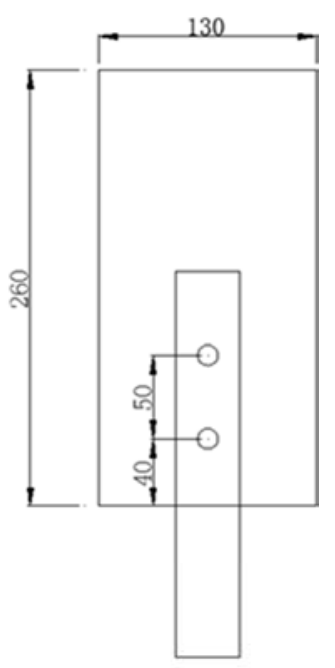

(b)

Figure 3. Configuration of nail joints: (a) loading perpendicular to stud grain; (b) loading parallel to stud grain.

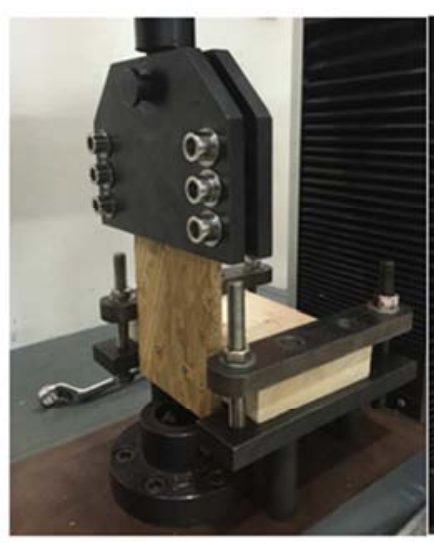

(a)

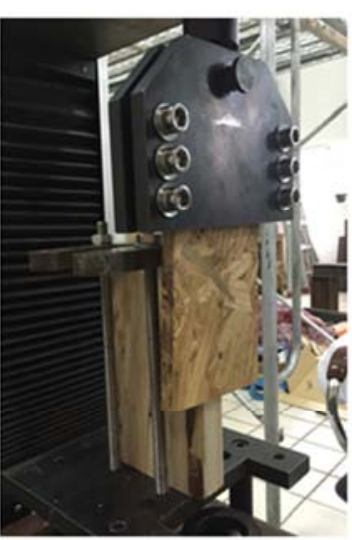

(b)
Figure 4. Nail joints shearing test: (a) load perpendicular to stud grain; (b) load parallel to stud grain.
As showed in Figure 4, in order to test the shear resistant strength of the nailed joints, devices suitable for the specimens were designed. Monotonic loading were applied to the specimens based on ASTM D 1761-12 [17]. The tests were carried out at a constant displacement rate of $2.54 \mathrm{~mm} / \mathrm{min}$ Tests were terminated when the load decreased to $80 \%$ of the loading peak value or the specimens failed. The load-displacement curves were recorded in computer automatically. The specimens were stretched until the panel and the studs were separated after failure to obtain the failure modes of nails, panels or studs.

\subsubsection{Shear Wall Loading Tests}

As showed in Table 3, shearing walls made of different stud size $(38 \mathrm{~mm} \times 89 \mathrm{~mm}$ and $38 \mathrm{~mm} \times 140 \mathrm{~mm})$ were loaded on microcomputer control electro-hydraulic servo wooden walls testing system (YAW-50Y/100J) to study the influence of stud size on lateral shearing resistance properties. Monotonic loading tests were conducted to find out the maximum displacement, peak loading value and failure mode. Cyclic loading tests were conducted to get the shearing wall energy dissipation capacity in unstable conditions. All shear walls, 2.44X2.44 $\mathrm{m}$ in dimension were constructed with SPF framing members and Canadian OSB panels with $12 \mathrm{~mm}$ thickness as the sheathing. The space between the vertical studs was $610 \mathrm{~mm}$. There were uplift anchors on top beam and floor beam to prevent uplift displacement. The monotonic load was applied under displacement control with a constant rate of $5 \mathrm{~mm} / \mathrm{s}$. Reversed cyclic loading tests were conducted following the protocol ISO-21581: 2010 [18]. As showed in Figure 5, the monotonic load was applied under displacement control with a constant rate of $5 \mathrm{~mm} / \mathrm{s}$. The load actuators drove the top stud in horizontal direction. 
Table 3. Test scheme of shear walls.

\begin{tabular}{llllll}
\hline & Stud cross size/mm & Stud spacing/mm & Panel type & Nail type & Load mode \\
\hline A1 & $38 \times 89$ & & & & monotonic \\
A2 & $38 \times 89$ & \multirow{2}{*}{$610 \mathrm{~mm}$} & \multirow{2}{*}{ cym Canadian OSB } & Strip nails & cyclic \\
B1 & $38 \times 140$ & & & monotonic \\
B2 & $38 \times 140$ & & & cyclic \\
\hline
\end{tabular}

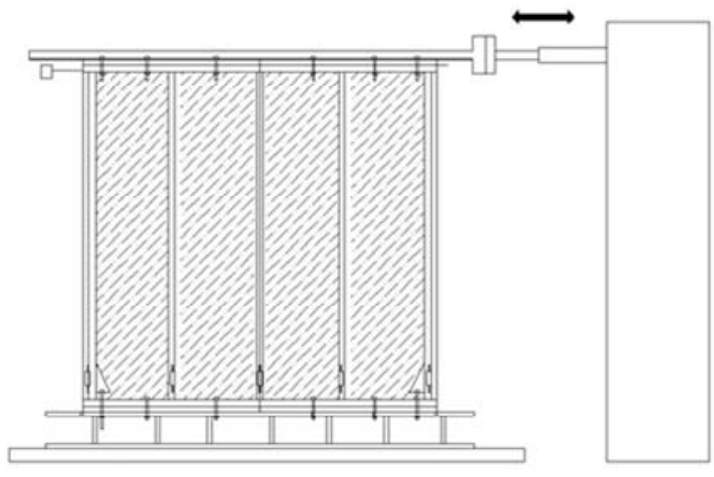

(a)

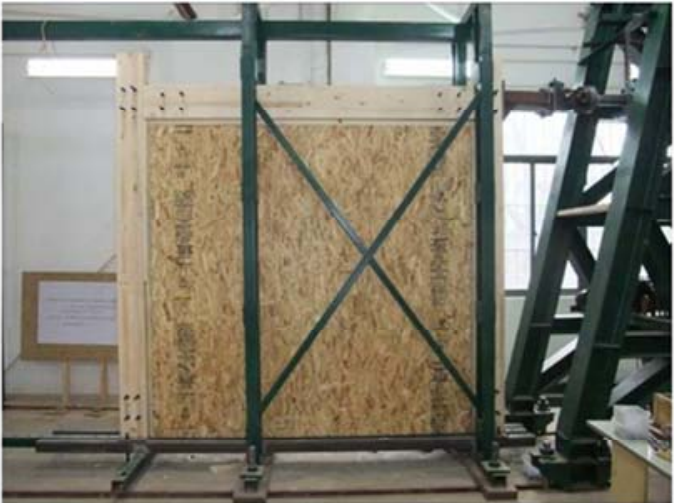

(b)

Figure 5. Shear wall test: (a) schematic representation of the test set-up; (b) test apparatus.

\section{Results and Discussion}

\subsection{Nailed Joints Test}

\subsubsection{Failure Modes}

The failures of the nail joint shearing test can be classified into three modes. The main failure mode was nail bent and

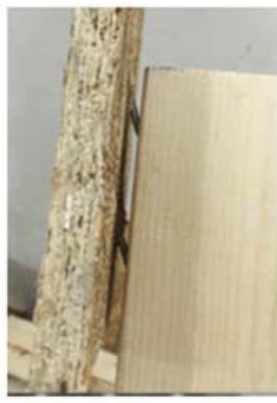

(a)

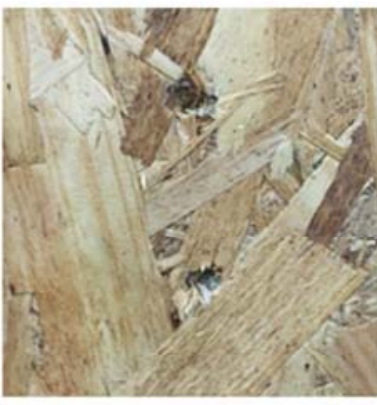

(b) withdrawn from the studs in Figure 6(a). As shown in Figure 6(b), the failure mode of the specimens with $9 \mathrm{~mm}$-thick OSB panels was nail heads pulled off the panels. The panels were too thin to bear the normal pressure of nail heads. As showed in Figure 6(c), some specimens were cracked from the nailing points due to the poor cleavage resistance of the sheathing panels.

Figure 6. The failure modes of nail joints: (a) nail bent and withdrawn from the studs; (b) nail heads pulled off the panels; (c) split off along the stud grain by nails.

\subsubsection{Loading-Displacement Curves}

The loading-displacement curves are illustrated in Figure 7. It can be found that the largest displacement of the nail joints load parallel to stud grain were larger than those perpendicular to stud grain. The nail joints load parallel to stud grain could maintain bearing capacity for longer time. It is because that when the loading direction was perpendicular to the stud grain, the studs were cracked apart at the nail shearing points or along the grain after the peak load. When the loading direction was parallel to the stud grain, nails went on splitting the stud along the grain to a certain distance after the peak point until studs were split in two or nails pulled off the studs, which could remain the loading force for a certain displacement [19].

Among specimens with the same sheathing panels but different nails, the strip nail joint samples got less discreteness before the peak loading points that the loading curves of the repeated specimens were stable, while the cures of coil nails and twist nails had a great discreteness. It is because the air nailer for coil nails is less accurate due to the nail gaps and poor fasten condition in the nailer, resulting to non-uniform nailing force. 

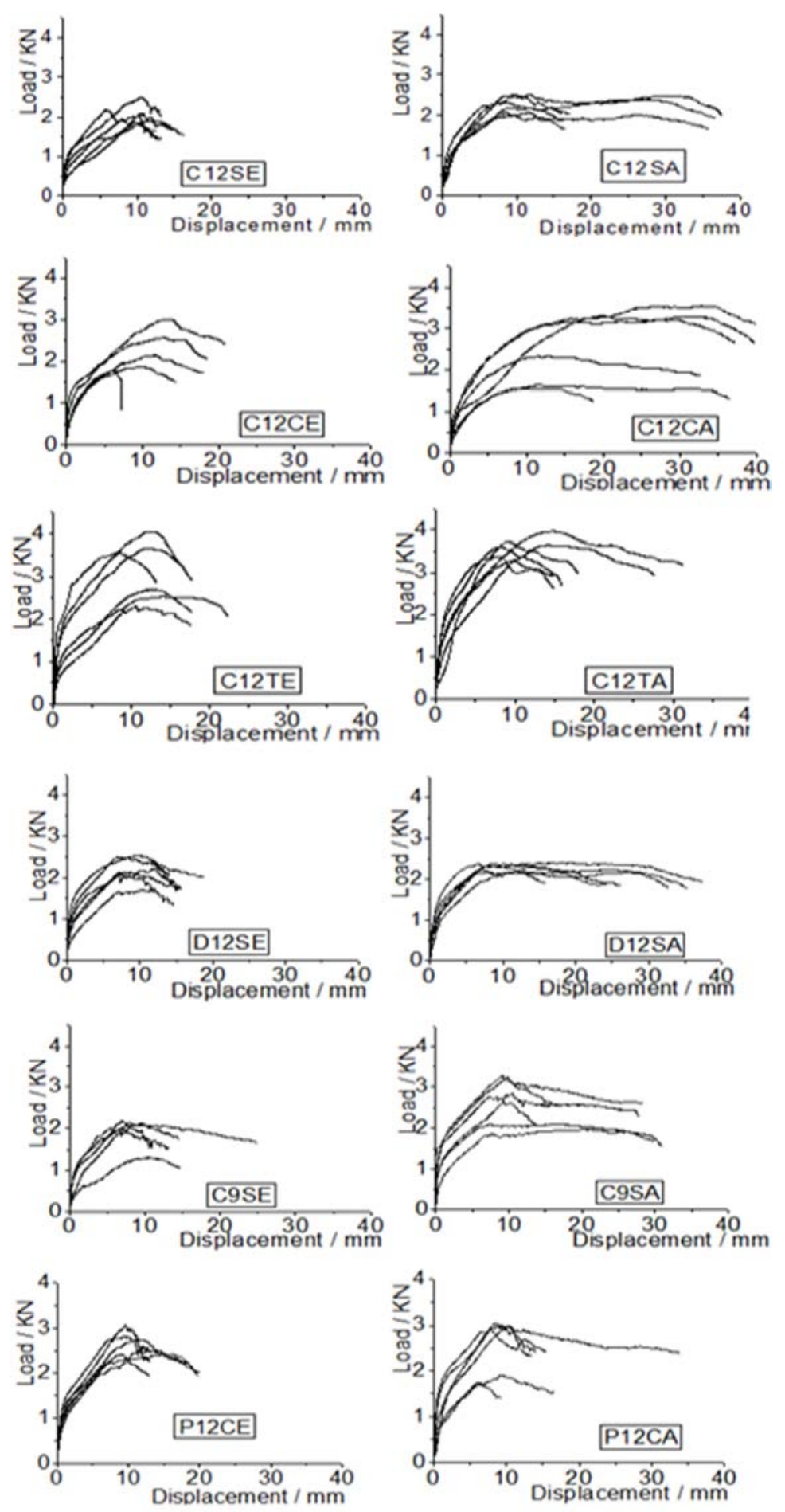

Figure 7. Load-displacement curves.

\subsubsection{Peak Load and Displacement}

The shearing load peak values $\mathrm{P}_{\max }$ and limit displacements $\mathrm{Du}$ of nailed joint specimens are listed in Table 4 .

Table 4. Nailed joints test result.

\begin{tabular}{lll}
\hline No. & $\mathbf{P}_{\max } / \mathbf{k N}$ & $\mathbf{D u} / \mathbf{m m}$ \\
\hline C12SA & $2.31(0.20)$ & $26.69(11.02)$ \\
C12SE & $2.09(0.24)$ & $13.26(2.18)$ \\
C12CA & $2.61(0.89)$ & $34.54(8.36)$ \\
\hline
\end{tabular}

\begin{tabular}{lll}
\hline No. & $\mathbf{P}_{\max } / \mathbf{k N}$ & $\mathbf{D u} / \mathbf{m m}$ \\
\hline C12CE & $2.22(0.47)$ & $16.86(5.37)$ \\
C12TA & $3.60(0.25)$ & $31.41(2.84)$ \\
C12TE & $3.13(0.71)$ & $18.75(2.26)$ \\
D12SA & $2.32(0.07)$ & $28.61(8.09)$ \\
D12SE & $2.20(0.31)$ & $15.10(2.23)$ \\
C9SA & $2.66(0.55)$ & $24.92(7.74)$ \\
C9SE & $1.85(0.33)$ & $16.39(5.16)$ \\
P12CA & $2.60(0.60)$ & $17.15(8.57)$ \\
P12CE & $2.68(0.27)$ & $16.09(3.49)$ \\
\hline
\end{tabular}

Numbers in parentheses represent standard deviations. 


\section{(i) Influence of Nail Types}

As showed in Table 4, the specimens with twist nails got the largest bearing capacity for both joints parallel and perpendicular to stud grain, then the coil nails. The maximum loading value ratio of different nails perpendicular to the grain C12TE:C12CE:C12SE is 1:0.71:0.68, and that ratio of different nails parallel to the grain C12TA:C12CA:C12SA is 1:0.72:0.64. In another words, the twist nails can bear the largest loads, then the coil nails and strip nails. The nail joints with strip nails could keep stable the best. The friction between studs and nails goes up with the increasing nail diameter. For twist nails, the lateral shearing failure is affected by wood fraction and shearing resistance simultaneously compared with common polished rod nails like coil nails and strip nails, which is in coincidence with Xiong's research [20].

\section{(ii) Influence of Panel Types}

Among the specimens that nailed by strip nails perpendicular to stud grain, the joints on China-produced structural plywood obtained the largest shearing loadings, then the joints on China-produced OSB. Among the samples loaded parallel to stud grain, the largest shearing loadings of the joints on structural plywood was similar with that on Canadian OSB. The largest shearing loading ratio of different panels nailed perpendicular to the grain P12CE:C12SE:D12SE is 1:0.78:0.82, and that ratio of different panels nailed parallel to the grain P12CA:C12SA:D12SA is 1:1:0.89. It is because the shearing resistance capacity of nail joint points is related to the mechanical properties of sheathing panels. The bearing capacity of nail joints increases with the elevated panel Young's modulus. According to Table 1, the Young's modulus of structural plywood is larger than that of OSBs, so the nail joint on structural plywood can bear the largest shearing loading of them three. And according to Que's research, the stiffness and joint ductility of structrural plywood were lower than that of OSB [21]. It also proved that the shearing properties of China-made OSB panels can also meet the requirement.

\section{(iii) Influence of Panel Thickness}

The shearing properties of nail joints specimens on $9 \mathrm{~mm}$ and 12mm-thick Canadian OSB panels were tested, respectively. It can be concluded from Table 4 that the capacity to avoid the nail pulled through the panel can be

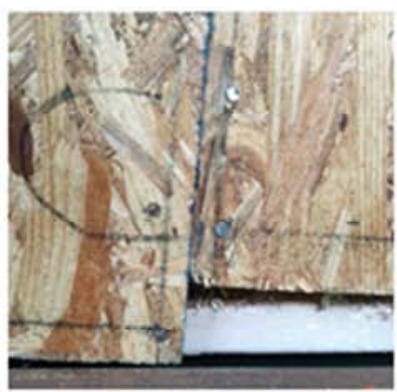

(a)

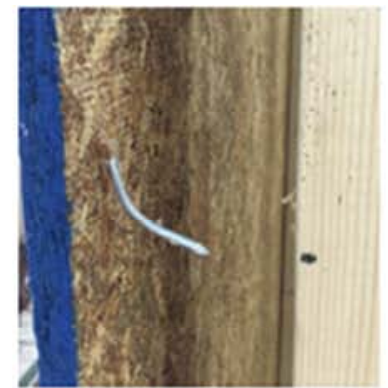

(b)

improved with the increasing panel thickness. At the same time, the thicker panel, the shallower nailed into stud, resulting to decreased pull-out resistance. Among the joints perpendicular to grain, the maximum bearing capacity of the samples with $12 \mathrm{~mm}$-thick panels was $13 \%$ larger than that with $9 \mathrm{~mm}$-thick panels. But among the joints parallel to grain, the maximum bearing capacity of the samples with $9 \mathrm{~mm}$-thick panels was $15.2 \%$ larger than that with $12 \mathrm{~mm}$-thick panels.

\subsection{Shear Wall Test}

\subsubsection{Monotonic Loading}

As showed in Figure 8, with the monotonic loading process going on, the nail joints failed as the consequence of relative displacement between the sheathing panels and the timber frame. Figure 9 illustrates the failure modes of shear walls under monotonic loading. The main failure mode included the dislocation of the panels (a), nails bent and withdrawn from the studs (b), nail heads pulled through the panels (c), nails shorn off $(\mathrm{d})$. When the loading exceeded the maximum bearing capacity of the nail joints between studs and bottom plate, the relative displacement uplift the studs and shear walls were wrecked when the nails were withdrew from the adjacent studs.

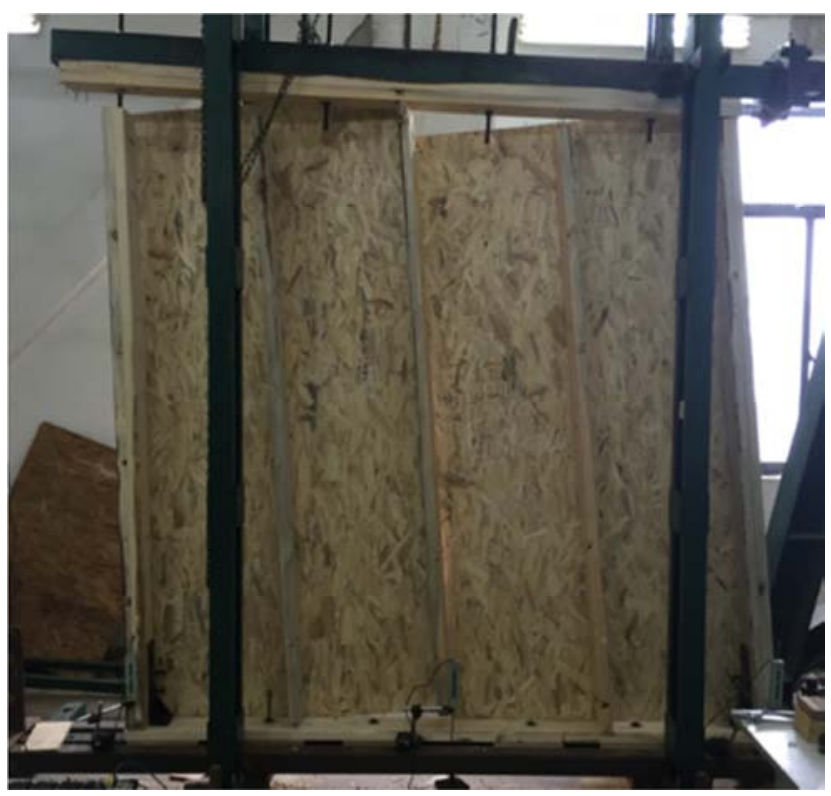

Figure 8. Failure of the shear walls.

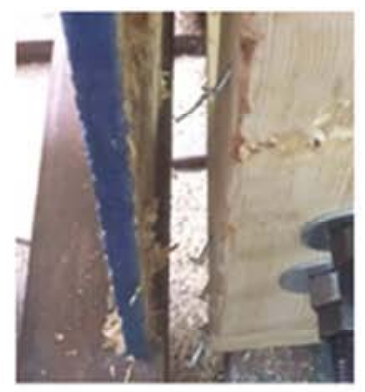

(c)

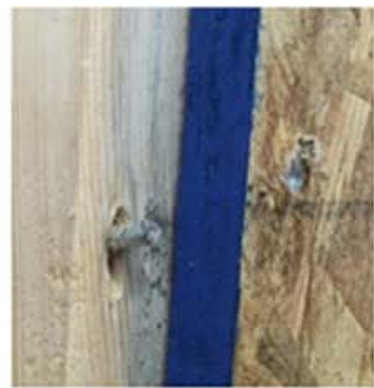

(d)

Figure 9. Failure of the shear wall: (a) relative displacement between panels (b) nail bent (c) nail heads pulled off the panels (d) nails shorn off. 
Table 5 illustrates the failure details of walls A1 and B1. It can be derived that the failure mode of shear walls with different stud size are similar. And the maximum shearing loading for A1 is $24.95 \mathrm{kN}, \mathrm{B} 1$ is $21.03 \mathrm{kN}$. The thicker wall is not corresponded to larger lateral shearing resistance.

Table 5. A1 and B1 failure details.

\begin{tabular}{ll}
\hline \multicolumn{2}{c}{ Failure details } \\
\hline A1 & $\begin{array}{l}\text { The bottom plate cracked. The nail joints on the bottom plate and between the panels were seriously destructed, nails were withdrew from the studs. } \\
\text { And a few nail heads were pulled through the panels. The middle stud got separated from the bottom plate. The upper part of the wall remained the } \\
\text { same. No obvious damage can be found in the upper part. } \\
\text { The failure of the wall was mainly the nails that connected the I panel and the middle stud were pulled through the panels. A few nails crushed the } \\
\text { studs. Nails connected II panel with side stud, bottom plate were pulled out. The nails connected top plate and panel remained the same. The middle } \\
\text { stud got separated from the bottom plate. }\end{array}$ \\
B1
\end{tabular}

I panel refers to which nearby the actuator and II panel refers to that far away from the actuator.

\subsubsection{Cyclic Loading}

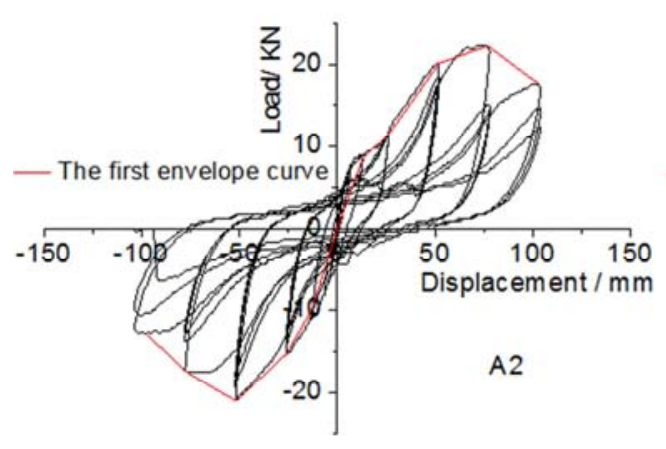

(a)

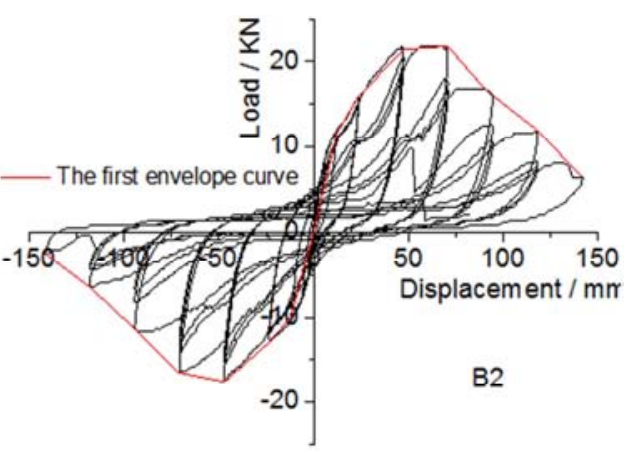

(b)

Figure 10. Hysteretic curves of shear walls: (a) A2 wall; (b) B2 wall.

The hysteretic curves of cyclic loading on shear walls are showed in Figure 10. The first envelope curve in the cyclic tests was obtained by connecting the maximum loading points in the hysteretic curves of each displacement level. As showed in Table 6 , the maximum loading value $F_{\max }$, bearing resistance $F v d$, resistant-lateral stiffness $K$, limit displacement $D u$, as well as energy dissipation capacity $E$ could be obtained based on the first envelope. Energy dissipation capacity that plays an important role in the lateral resistance ability is the area of the curve surrounded. Stiffness $K$ can be calculated from the following equation.

$$
K=\frac{0.3 F_{\max }}{D_{40 \% F_{\max }}-D_{10 \% F_{\max }}}
$$

Where $D_{40 \% F_{\max }}$ and $D_{10 \% F_{\max }}$ are the displacement values at the $40 \%$ and $10 \%$ points of the maximum load.

Table 6. Shearing test results on the shear walls.

\begin{tabular}{|c|c|c|c|c|c|c|c|c|c|c|}
\hline & & $F_{\max }$ & $(\mathbf{K N})$ & Fvd & $(\mathrm{KN} / \mathbf{m})$ & $D u$ & & $K \quad(\mathrm{KN} / \mathrm{m})$ & & $E(\mathbf{K N} \cdot \mathbf{m m})$ \\
\hline \multirow{2}{*}{ A2 } & Push & 22.26 & 22.26 & 9.12 & \multirow{2}{*}{8.87} & 101.97 & \multirow{2}{*}{91.02} & 612.80 & \multirow{2}{*}{684.96} & \multirow{2}{*}{10492} \\
\hline & Pull & 21.02 & 22.20 & 8.61 & & 80.07 & & 757.11 & & \\
\hline \multirow{2}{*}{ B2 } & Push & 21.86 & \multirow{2}{*}{21.86} & 8.96 & \multirow{2}{*}{8.08} & 70.47 & \multirow{2}{*}{76.28} & 954.62 & \multirow{2}{*}{888.93} & \multirow{2}{*}{13338} \\
\hline & Pull & 17.55 & & 7.19 & & 82.09 & & 823.24 & & \\
\hline
\end{tabular}

This test investigated the effect of different stud size on shear wall lateral shearing resistance properties. As showed in Table 6 , the maximum lateral resistance loading of A2 are $1.8 \%$ and $19.7 \%$ larger than those of B2 in push and pull direction, respectively. And the maximum loading of B2 is little bit smaller than that of $\mathrm{A} 2$, which might be caused by experiment systemic error. It indicates that the larger size stud could not improve the lateral resistance. It is because the lateral shearing tests are conducted in horizontal direction, the strength of which is only related to the nail joint capacity. The increase in wall-thick direction has no concern with horizontal loading.
However, the stiffness of specimen B2 is $29.8 \%$ larger than that of A2. As the stud size has been changed, the distance of nails in a row got wider, and the contact area of the stud with the top and bottom beams got larger. It could be the reason to the increasing stiffness. Moreover, the energy dissipation capacity is increased with larger stud size that the energy dissipation of B2 is $27.1 \%$ larger than that of $\mathrm{A} 2$.

\section{Conclusions}

In this paper, different factors that might affect nail joint 
behavior and lateral shearing properties in light wooden frame walls are investigated experimentally. The failure modes and loading characteristics are studied to obtain the influences of nails, stud and sheathing panels. It is concluded as follow:

1) The shear bearing capacity of nail joints is affected by nail types. The twist nails could bear the largest shearing loadings compared with coil nails and strip nails. The shear bearing capacity for nail joint parallel to stud grain is larger than that perpendicular to the grain by comparing the largest displacement.

2) The panel thickness has great influence on nail joint bearing capacity and shearing failure modes. Thicker sheathing panels could bear larger lateral shearing loads compared with thinner ones. The nail joint on China-produced structural plywood got the largest shearing resistance value compared with those on Canada imported OSB and China-produced OSB, which demonstrated the safe reliability of various structural material choices.

3) The lateral resistance cannot be enhanced by increasing stud size. The energy dissipation capacity can be increased by rising the stud size that the stiffness of wooden frame walls with studs of cross size $38 \times 140 \mathrm{~mm}$ is $28.9 \%$ larger than the wall with $38 \times 89 \mathrm{~mm}$ studs. And the seismic resistance properties can be improved as well. In this way, walls with thicker frame are suggested to fulfill higher structural stiffness demand.

4) With nail joint and material parameter design optimized, the seismic design and calculation of light wooden frame structure can also be improved in further study so as to progress toward multistory building with higher bear capacity and multifunction.

\section{Acknowledgements}

The authors gratefully acknowledge the support from Research Program supported by Housing and urban-rural development "Application analysis of timber structure in new architecture industrialization practice based on different structural materials and system" (2016-K5-003) and the research project supported by Shanghai Construction Group "Application research on the wooden frame composite wall in multi-high story hybrid timber structure based on prefabrication" (16JCYJ-09).

\section{References}

[1] Dinehart D W, III H W S. Comparison of static and dynamic response of timber shear walls [J]. Journal of Structural Engineering, 1998, 124(6): 686-695.

[2] Folz B, Filiatrault A. Cyclic analysis of wood shear walls [J]. Journal of Structural Engineering, 2001, 127(4): 433-441.

[3] Lam F, Prion H G L, He M. Lateral resistance of wood shear walls with large sheathing panels [J]. Journal of structural engineering, 1997, 123(12): 1666-1673.

[4] Van De Lindt J W. Evolution of wood shear wall testing, modeling, and reliability analysis: Bibliography [J]. Practice Periodical on Structural Design and Construction, 2004, 9(1): 44-53.

[5] Humbert J, Boudaud C, Baroth J, et al. Joints and wood shear walls modelling I: Constitutive law, experimental tests and FE model under quasi-static loading [J]. Engineering Structures, 2014, 65(3):52-61.

[6] Richard N, Daudeville L, Prion H, et al. Timber shear walls with large openings: experimental and numerical pre. [J]. Canadian Journal of Civil Engineering, 2002, 29(5): 713-724.

[7] American forest \& paper association. National Design Specification for Wood Constructions [M]. American Forest \& Paper Association, Washington, D. C. 2005, 174p.

[8] Winistorfer S G, Soltis L A. Lateral and Withdrawal Strength of Nail Connections for Manufactured Housing [J]. Journal of Structural Engineering, 1994, 120(12):3577-3594.

[9] Rammer D R, Winistorfer S G, Bender D A. Withdrawal Strength of Threaded Nails [J]. Journal of Structural Engineering, 2001, 127(4):442-449.

[10] Skulteti M J, Bender D A, Winistorfer S G, et al. Withdrawal strength of ring-shank nails embedded in southern pine lumber [J]. 1997, 40(2):451-456.

[11] Mclain T E. Design axial withdrawal strength from wood. II. Plain-shank common wire nails.[J]. Forest Products Journal, 1997.

[12] Fujita M, Komatsu K, Kawamoto N. Bearing characteristics of glued-laminated-timber and laminated-veneer lumber with a steel rod [R]. Research Bull of Hokkaido University. 1995. 41:261-270.

[13] Peter John Cates. Dowel bearing strength and bolted connection behavior of oriented strand lumber [D]. Master thesis of Washington State University. Department of civil and environmental engineering. 2002.

[14] Winistorfer S G. Practical considerations of dowel bearing strength and annular ring/fastener orientation.[J]. Forest Products Journal, 1995, 45(7-8):64-68.

[15] Ministry of Construction of P. R, C. GB 50005-2003 Code for design of timber structure [S]. Beijing: China Architecture \& Building Press, 2005.

[16] China State Forestry Administration, LY/T 1580-2000. Oriented strand board [S]. Beijing: China Standard Press, 2010.

[17] ASTM D1761-12 Standard test methods for mechanical fasteners in wood. America Society of Testing and Materials. West Conshohocken, 2012.

[18] ISO 21581:2010: Timber structures - Static and cyclic lateral load test methods for shear walls, 2010.

[19] Yan L, Zou X J, She C G. Performance of the Nail Joints on Wood Frame Shear Walls [J]. Advanced Materials Research, 2011, 255-260:350-354.

[20] Xiong H. Cyclic Tests Research on Nail Joints of Light Wood Frame Structures [J]. Structural Engineers, 2011.

[21] Que Z, Yang L, Zhao D, et al. Experimental study of nail joints of shear walls under different cladding conditions in wood frame structures [J]. Building Structure, 2014, 44(9):93-96. 